\title{
PENGENALAN KOMPONEN OTOMOTIF DALAM BAHASA INGGRIS BAGI PEMUDA DAERAH WONOKROMO II
}

\author{
Dewanti Ratna Pertiwi
}

\author{
Program Studi Teknik Mesin \\ Sekolah Tinggi Teknologi Adisutjipto \\ Jalan Janti Blok R Lanud Adisutjipto Yogyakarta \\ dewantiratna@stta.ac.id
}

\begin{abstract}
The position of English as the first international language encourages some products use this as the main language to describe the specification. One of them is automotive spare parts. As the products used by a lot of people in Indonesia, knowing the automotive components in English is important. A youth community in Wonokromo II Pleret Bantul Yogyakarta is one of the communities which needs English training on automotive components. This community consists of the youths with various backgrounds from senior high school students to university students. Pleret is potential for developing automotive components further because there are some centers of automotive spare parts that English training automotive components is expected to open opportunity for the youths to develop automotive sector more widely either by offline or online shops. In this community service, the training focuses on the automotive parts supported by authentic learning media, pictures, video, and digital learning. The training is expected to give the basic technical terms that the targets master automotive sector more widely.
\end{abstract}

\begin{abstract}
Abstrak
Posisi bahasa Inggris sebagai bahasa internasional nomor satu di dunia menjadikan berbagai produk menggunakan bahasa ini sebagai bahasa utama dalam menjelaskan spesifikasi. Salah satu produk yang banyak menggunakan istilah bahasa Inggris adalah kendaraan bermotor. Sebagai produk yang digunakan oleh mayoritas masyarakat Indonesia, mengenal komponen otomotif pada kendaraan bermotor dalam bahasa Inggris dianggap penting. Persatuan muda mudi Wonokromo II Pleret Bantul Yogyakarta merupakan salah satu masyarakat yang dipandang perlu mendapat pengenalan komponen otomotif dalam bahasa Inggris. Komunitas ini terdiri dari pemuda dengan berbagai lapisan usia antara usia sekolah menengah atas hingga perguruan tinggi. Potensi daerah Pleret memungkinkan pengembangan sektor otomotif lebih jauh karena terdapat beberapa sentra penyedia sparepart kendaraan bermotor sehingga pengenalan komponen otomotif diharapkan mampu membuka peluang para pemuda untuk mengembangkan usaha bidang otomotif baik offline maupun online. Dalam kegiatan ini, pengenalan difokuskan pada komponen-komponen (part) otomotif yang didukung oleh media pembelajaran autentik, gambar, video, dan online (digital). Pengenalan komponen-komponen otomotif diharapkan dapat memberikan dasar kosa kata sehingga lebih menguasai bidang otomotif secara luas.
\end{abstract}

Kata kunci: komponen, otomotif, bahasa Inggris 


\section{Latar Belakang Masalah}

Bahasa Inggris merupakan bahasa internasional yang mendorong berbagai pihak untuk terus mengembangkan penguasaan bahasa asing ini sehingga mampu bersaing secara global. Usaha di berbagai sektor salah satunya otomotif merupakan bidang usaha yang sering menggunakan bahasa Inggris sebagai bahasa asing utama. Tidak dapat dihindari bahwa sektor usaha otomotif di daerah dengan skala kecil mulai mengembangkan usaha ke luar daerah hingga suatu saat berusaha bersaing secara global luar negeri. Salah satu daerah yang berpotensi mengembangkan sektor otomotif adalah Wonokromo, Pleret, Bantul.

Sebagai makhluk sosial, masyarakat membentuk suatu kelompok yang memiliki visi dan misi yang sama. Persatuan muda mudi Wonokromo II ini berlokasi di RT 05 Wonokromo II, Pleret, Bantul. Organisasi ini dibentuk oleh pemerintah sejalan dengan kebijakan otonomi daerah. Fluktuasi keanggotaan dan kegiatan terjadi pada kelompok ini. Organisasi ini terdiri dari seorang ketua, dua sekretaris, dua bendahara, dan beberapa seksi salah satunya seksi pengembangan keterampilan sebagai wadah berbagi pengalaman dan keterampilan antar anggota.

Keanggotaan persatuan muda mudi Wonokromo II bervariasi. Warga yang menempuh pendidikan sekolah menengah atas hingga lulus perguruan tinggi secara otomatis akan menjadi anggota. Jumlah pemuda tingkat SMA adalah 27, kuliah 13 dan lulusan SMA 14.

Jumlah sebaran anggota tersebut dipandang sangat strategis untuk membekali anggotanya dengan berbagai keterampilan. Mengingat daerah Wonokromo yang berpotensi akan bidang otomotif, pemberian keterampilan berbahasa Inggris tentang otomotif diharapkan mampu mendukung perluasan lapangan kerja sehingga baik anggota yang setelah lulus sekolah menengah atas langsung bekerja maupun yang melanjutkan ke perguruan tinggi mampu mengembangkan potensi daerah di bidang otomotif ke pasar global. Berdasarkan survei, belum ada pelatihan bahasa Inggris terkonsentrasi pada pengenalan komponen otomotif selama ini.

Komitmen organisasi untuk meningkatkan kualitas anggota dari tahun ke tahun tidak lepas dari adanya berbagai usaha memberikan program-program pendidikan berbasis otomotif. Sebagai kelompok yang berdiri tahun 2010, wadah ini terus menerus melakukan terobosan untuk meningkatkan kualitas anggotanya. Salah satu faktor usaha tersebut dapat dilakukan dengan memberikan program bahasa Inggris bertujuan spesifik atau dikenal dengan English for Specific Purposes (ESP). ESP diselenggarakan berdasarkan analisa kebutuhan mitra (need analysis). Meskipun ESP berbeda dengan bahasa Inggris umum, muatan umum tersebut harus terintegrasi pada ESP sehingga sasaran mampu menguasai keduanya (Chen, 2008). Basturkmen (2006) menambahkan bahwa subjek ESP dan target penguasaan adalah tujuan utama ESP karena ESP diperlukan pada saat mitra di lingkup program pelatihan dan pada saat mitra tersebut telah lulus dan bekerja. Huhta, dkk. (2013) mengemukakan pada ESP siswa melengkapi serangkaian tugas di mana konteks pembelajaran berasal dari lingkungan profesional yang familier dengan mereka.

Program pengabdian masyarakat ini bertujuan mengenalkan pembelajaran bahasa Inggris ESP berbasis otomotif. Salah satu tahapan mendasar pada ESP otomotif adalah pengenalan istilah-istilah bidang otomotif. Dalam kegiatan ini, pengenalan akan difokuskan pada komponen-komponen (part) otomotif yang didukung oleh media pembelajaran autentik, gambar, video, dan online. Pengenalan komponen-komponen otomotif diharapkan dapat memberikan dasar kosa kata sasaran sehingga mereka lebih menguasai bidang otomotif secara luas. 


\section{Masalah}

Sebagai sebuah kelompok yang tergolong baru dan mengalami pasang surut keaktifan program dan anggota, persatuan muda mudi Wonokromo II ini masih menemui beberapa kendala. Organisasi ini memerlukan bahan ajar dan teknik pengajaran bahasa Inggris berbasis otomotif berupa materi autentik, audio, video, online, dan materi pendukung lainnya. Bahan ajar tersebut dipandang membantu anggota mempelajari bahasa Inggris otomotif. Teknik pengajaran juga perlu inovasi mengingat beberapa anggota di program ini berasal dari latar belakang ekonomi, sosial, dan pendidikan yang variatif.

\section{Metode}

Solusi yang ditawarkan pada organisasi ini adalah memberikan pembelajaran pengenalan komponen otomotif menggunakan bahasa Inggris. Pembelajaran ini menggunakan media autentik, gambar, video, dan online untuk memudahkan peserta mengidentifikasi komponen otomotif dalam bahasa Inggris. Selain itu, metode yang digunakan adalah menggunakan games agar mitra kegiatan lebih tertarik dan mengurangi tingkat kebosanan.

Pada tahapan pre-teaching, peserta diminta memberi polling online tentang kondisi industri otomotif di Wonokromo II. Setelah itu, pembelajaran menggunakan media autentik dan gambar. Peserta melihat beberapa spare part motor dan mobil langsung kemudian dilengkapi media gambar untuk menambah jumlah bagian yang dikenalkan. Pada tahap ini, peserta juga diberi latihan untuk menjodohkan gambar dengan nama spare part. Pada tahapan whilst-teaching, untuk membuat pembelajaran lebih menarik, beberapa video diputar kemudian peserta mencermati komponen tersebut. Salah satu video mengenalkan perbedaan istilah otomotif pada bahasa Inggris Amerika dan British. Dengan demikian, peserta mampu membedakan dan mengidentifikasi persamaan istilah otomotif Amerika dan British. Pada tahapan post-teaching, peserta diberikan projek kelompok untuk membuat lapbook berisi komponen otomotif dan bermain peran menjual barang tersebut. Lapbook terbuat dari stopmap sederhana, kemudian diberi gambar otomotif yang didesain secara kreatif. Selain itu, peserta juga diberi review berupa kuis online.

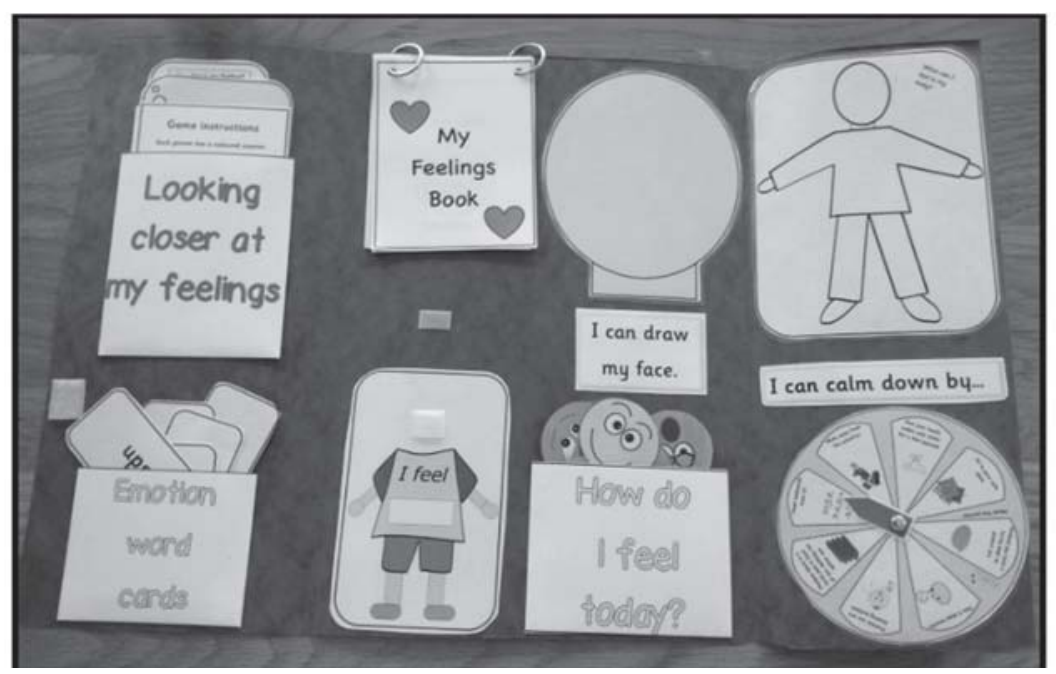

Gambar 1. Contoh lapbook 


\section{Hasil}

Pengabdian masyarakat dilaksanakan pada hari Sabtu tanggal 7 Juli 2018 di Laboratorium Komputer, STT Adisutjipto. Peserta terdiri dari 19 pemuda Wonokromo II. Pada tahapan pre-teaching, peserta diberi pertanyaan tentang kondisi industri otomotif di Wonokromo melalui polling online sebagai berikut.

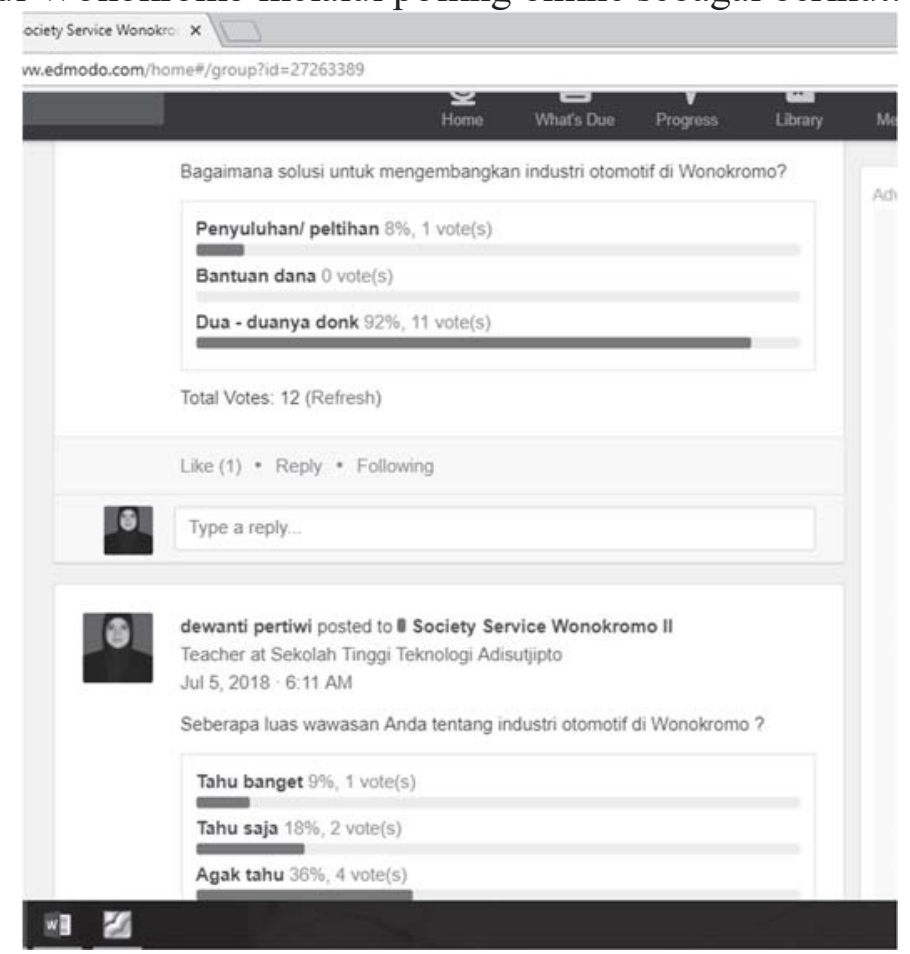

Gambar 2. Hasil polling

Polling online menggunakan aplikasi Edmodo. Peserta tampak antusias menggunakan aplikasi ini dalam merespon polling online. Setelah selesai, pembahasan setiap polling dilakukan secara klasikal dilanjutkan mengidentifikasi komponen otomotif autentik yang disediakan di kelas. Sejumlah media gambar diberikan untuk menambah jumlah komponen otomotif yang dikenalkan. Peserta diberi gambar komponen otomotif untuk diberi label nama masing-masing.

Pada tahap whilst-teaching, video tentang komponen mobil diputar. Peserta tampak tertarik mengamati komponen yang dikenalkan melalui video tersebut. Kemudian diadakan tanya jawab peserta secara acak diminta menutup catatan dan maju menulis komponen dalam bahasa Inggris dan Indonesia di papan tulis. Respon peserta variasi, ada yang percaya diri, semangat, ada juga yang harus didorong berpartisipasi. Proses dilanjutkan hingga selesai kemudian dibahas secara klasikal. Pada aktivitas ini, koreksi yang membangun diberikan agar peserta tidak merasa minder dan tetap termotivasi belajar bahasa Inggris. Untuk memberikan pengetahuan perbedaan istilah Amerika (US) dan Inggris (UK), video 2 diputarkan. Pada video ini, kata-kata yang dikenalkan tidak hanya pada komponen otomotif tetapi juga istilah kelalu-lintasan seperti yang tergambar pada bagian berikut. 


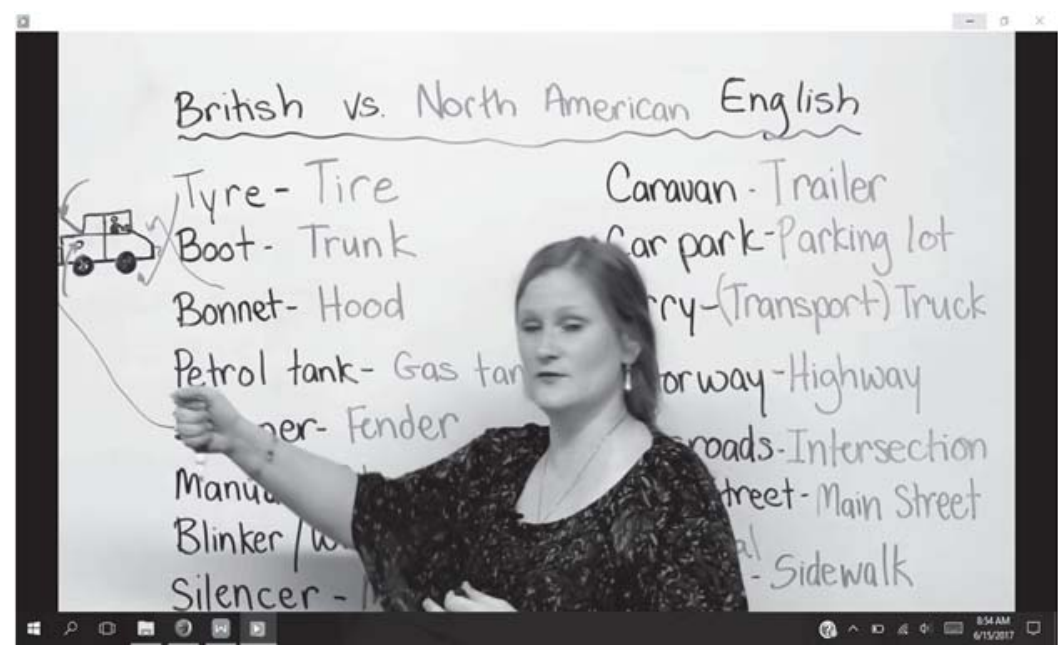

Gambar 3. British VS American English

Pada tahapan post-teaching, peserta diberikan projek kelompok untuk membuat lapbook berisi komponen otomotif dan bermain peran menjual barang tersebut. Lapbook terbuat dari stopmap sederhana, kemudian diberi gambar otomotif yang didesain secara kreatif. Semua peserta antusias membuat lapbook dan berusaha menjual produk otomotif mereka dengan maksimal. Beberapa hadiah disediakan untuk kelompok yang berhasil memikat pembeli dan menjual produk. Selain itu, peserta juga diberi review berupa kuis online tentang bahasa Inggris dengan hasil sebagai berikut

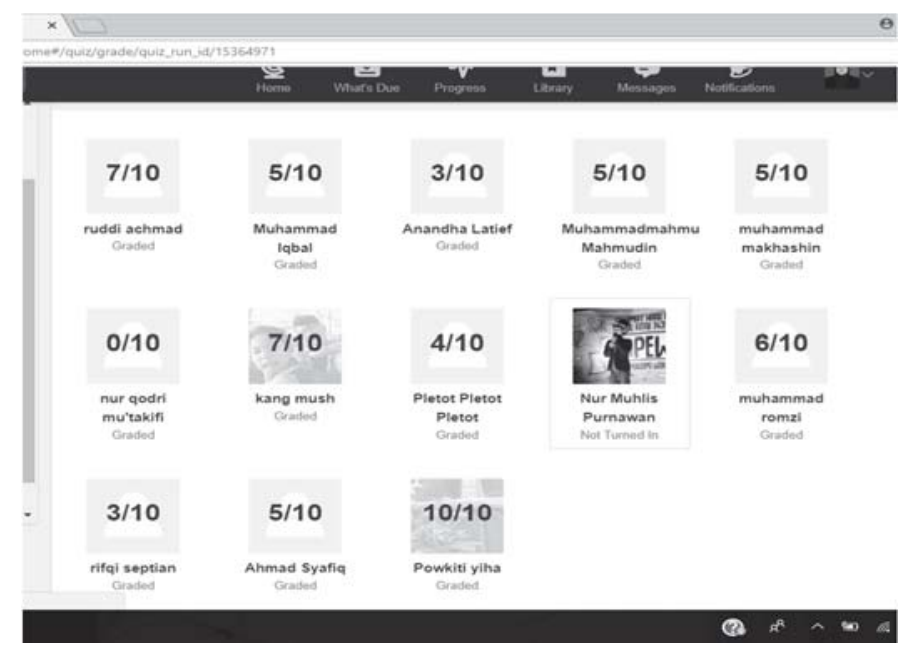

Gambar 4. Review kuis online

Evaluasi kegiatan pengabdian masyarakat menyimpulkan beberapa luaran. Motivasi dalam belajar bahasa Inggris otomotif, pengetahuan peserta tentang komponen otomotif, dan keterampilan dalam mengidentifikasi komponen otomotif menggunakan bahasa Inggris perlu ditingkatkan. Selain itu, tersedianya modul latihan dan materi online untuk mendukung pengetahuan bahasa Inggris otomotif perlu dikemas menarik agar pemuda semangat dalam meningkatkan keterampilannya. 


\section{Kesimpulan}

a. Kegiatan pengabdian masyarakat ini dapat berjalan lancar dengan adanya dukungan dari peserta dan pimpinan organisasi. Ketersediaan peserta untuk open minded terhadap bahasa Inggris mendasari kelancaran kegiatan ini. Selain itu, kemampuan peserta untuk mengakses media online menambah kelancaran pengabdian ini.

b. Beberapa hambatan dapat diatasi selama kegiatan ini. Pengetahuan dan kemampuan bahasa Inggris peserta yang rendah membuat pemateri perlu mengulang instruksi dan penjelasan secara pelan-pelan, diulang, dan terperinci. Teknik pembelajaran, materi yang variasi, media online, dan hadiah untuk peserta yang aktif mampu memberikan solusi pada hambatan-hambatan tersebut.

\section{Daftar Pustaka}

[1] Basturkmen, H. (2006). Ideas and options in English for specific purposes. New Jersey: Lawrence Erlbaum Associates.

[2] Chen, C. M. (2008). The difficulty of university English courses and English for specific purposes: From the view of policy and administration. English Career, $28,12-16$.

[3] Huhta, dkk. (2013). Need Analysis for Language Course Design: A holistic approach to ESP. Cambridge: CUP. 